\title{
Nonfatal Barium Intravasation into the Portal Venous System during Barium Enema Examination
}

\author{
Mari TAKAHASHI, Katsuyuki FukUdA, Yuji OHKUbo, Naoki ToKUHIRO, \\ Ryosei TsuchiYA, Masanobu YoshIE and Yasuo HIRAI
}

\begin{abstract}
We report a case of barium intravasation in a 66-yearold patient. Unenhanced computed tomography (CT) scan revealed barium and air emboli in portal veins and liver. We believe he survived because his liver prevented inflow of barium into the systemic circulation. To the best of our knowledge, this is the 23rd reported case of venous barium intravasation in the last 50 years. Because all 23 patients had bowel disease or diverticulitis, we conclude barium enema should be used cautiously in such patients.
\end{abstract}

(Internal Medicine 43: 1145-1150, 2004)

Key words: barium enema, barium intravasation, septic shock, embolization

\section{Case Report}

A 66-year-old man was admitted to Matsudo City Hospital on March 4, 2002, with shock after several days of diarrhea, malaise, chills and fever. Physical examination revealed blood pressure of $63 / 29 \mathrm{mmHg}$, pulse of 68 beats/min and temperature of $31.8^{\circ} \mathrm{C}$. Bloody stool appeared intermittently. Laboratory evaluation revealed a white blood cell count of $16,800 / \mu \mathrm{l}$, metabolic acidosis ( $\mathrm{pH} 6.85$ ), blood urea nitrogen concentration of $102.2 \mathrm{mg} / \mathrm{dl}$, creatinine concentration of $13.9 \mathrm{mg} / \mathrm{dl}$ and C-reactive protein (CRP) concentration of $24.0 \mathrm{mg} / \mathrm{dl}$. After 7 days of antibiotic treatment with imipenem and continuous hemodiafiltration, the patient recovered from shock. The shock was likely caused by enterogenous sepsis because of chronic diarrhea and intermittent bloody stool, but some blood and stool cultures were negative for pathogens. No X-ray and CT scan examinations revealed an infectious focus (Fig. 1). When he was discharged from the hospital on April 13, he was scheduled for barium enema and colon fiber examinations to investigate the cause of the diarrhea and intermittent bloody stool. Barium enema was performed on April 24. During the examination, venous barium intravasation from sigmoid colon into the portal venous system via the inferior mesenteric vein was recognized on the image intensifier (Figs. 2 and 3). A 2.5-cm mass was also recognized at the sigmoid colon (Fig. 4). The patient lost consciousness temporarily. The examination was immediately discontinued, and he was moved to the emergency room.

In the emergency room, the patient's condition improved. He was nearly fully alert (Glasgow Coma Scale E4V5M6), with a blood pressure of $180 / 106 \mathrm{mmHg}$, pulse of 84 beats/ min and temperature of $37.8^{\circ} \mathrm{C}$. His white blood cell count was $9,700 / \mu \mathrm{l}$. Fibrin degradation product was elevated to $41.7 \mu \mathrm{g} / \mathrm{ml}$. Urea, electrolytes and liver function parameters were within normal limits. Unenhanced abdominal CT scan revealed barium and air emboli in portal veins and liver tissue (Fig. 5). Abdominal ultrasonography also revealed multiple high echoic lesions caused by air emboli, but abdominal doppler ultrasonography showed no hemodynamic change in the main portal vein. Portal venography via the supra mesenteric artery was performed 3 hours after the barium enema. The portal vein was patent, and no embolus was recognized. No anomalous vessels were found, and the intravasation point was not revealed.

Blood culture specimen were obtained and treatment with antibiotics (imipenem $1 \mathrm{~g} /$ day intravenous drip, kanamycin and polymyxin B per os) was started. Growth of Escherichia coli was verified later. Although the air embolus in portal veins disappeared the next day, the barium deposit in the liver did not change (Fig. 6). Liver function parameters remained within normal limits. There was no clear sign of infection, although CRP had increased slightly. Peritoneotomy was performed 6 days after the barium enema to determine the cause of intravasation such as deformity, to resect the point of intravasation, and to perform liver biopsy. He was found to have an inflamed swollen sigmoid colon, but the

From the Department of Gastroenterology, Matsudo City Hospital, Matsudo

Received for publication February 2, 2004; Accepted for publication July 4, 2004

Reprint requests should be addressed to Dr. Mari Takahashi, the Department of Dermatology, Chiba University, 1-8-1 Inohana, Chuo-ku, Chiba 260-8677 


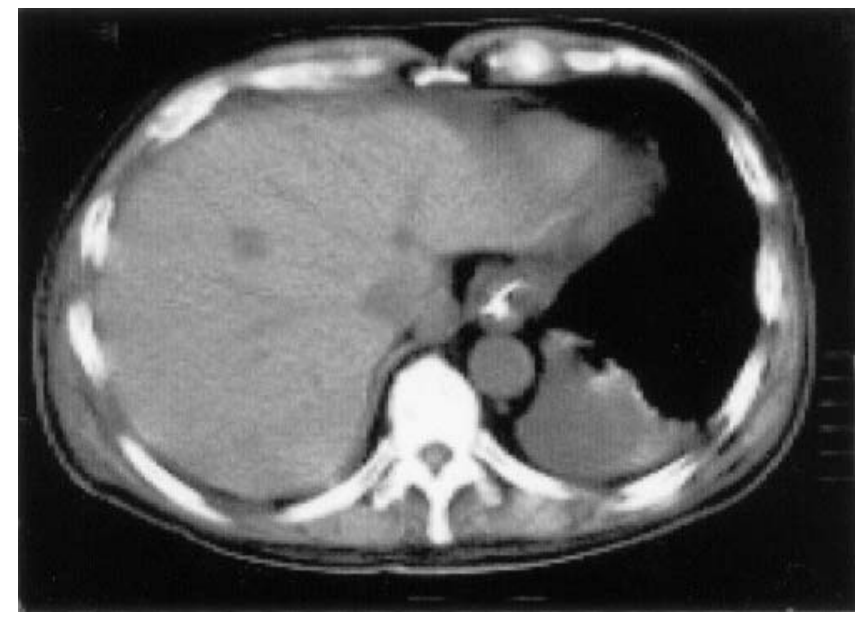

Figure 1. Unenhanced abdominal CT performed at the first time admission did not reveal an infectious focus.

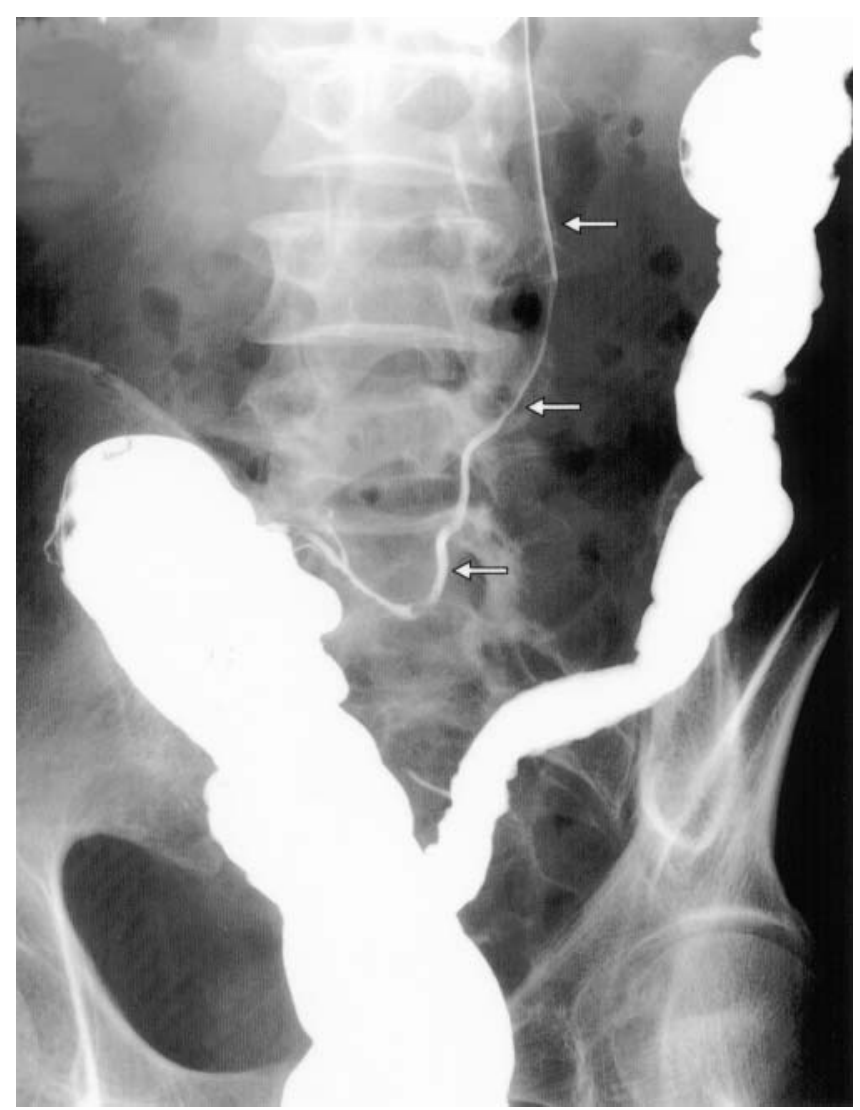

Figure 2. Contrast material is seen filling a tubular structure to the oral side (arrows).

vessels, mesenterium and liver showed nothing abnormal. Sigmoidectomy with end-to-end anastomosis was performed. A 25-mm sigmoid polyp and multiple ulcers 1 to $5 \mathrm{~cm}$ in size were found (Fig. 7A). A small fragment of liver tissue

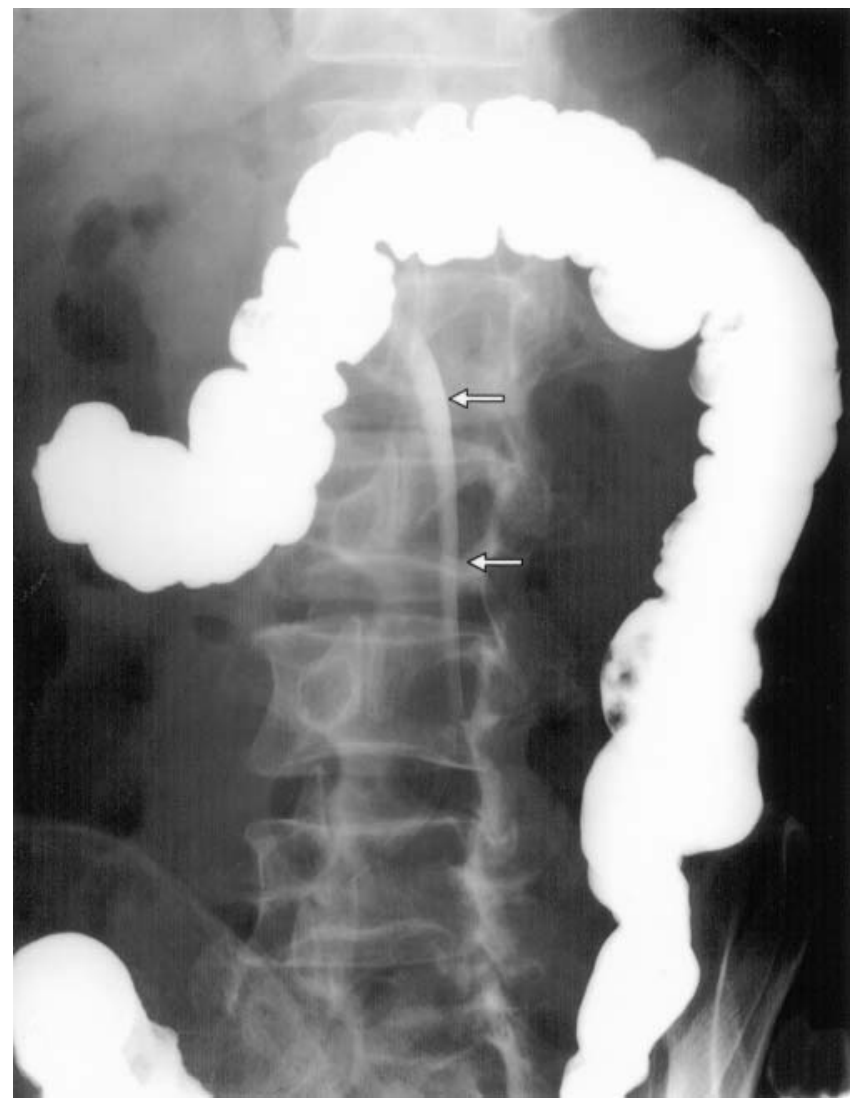

Figure 3. Barium is seen in the inferior mesenteric vein (arrows).

was removed from lateral segment for biopsy.

Pathologic examination showed the sigmoid polyp with carcinoma in situ (Fig. 7C), and the ulcers reached the submucosa and partially reached the muscular layer. Though the cause of appearance of the ulcers were not diagnosed, it was only supposed that they had likely existed for 1 to 2 months from their fibrous change (Fig. 7B). The barium inflow could not be pointed out. Liver biopsy microscopic examination showed enlargement of Glisson's sheath, inflammatory cell invasion and barium sulfate particles $(30 \mu \mathrm{m})$ in many portal veins (Fig. 8).

The patient improved after the last operation and was discharged 27 days later, free from symptoms and with the normal liver function. After 3 months, colon fiber examination was performed and showed nothing abnormal in the rest of his colon. After 18 months, CT scan examination showed almost no change in the liver barium deposit (Fig. 9).

\section{Discussion}

Although barium enema is a relatively safe examination, barium intravasation is a serious complication for some patients. During the last 50 years, 22 cases of venous barium intravasation have been reported; the present case is the 23rd 


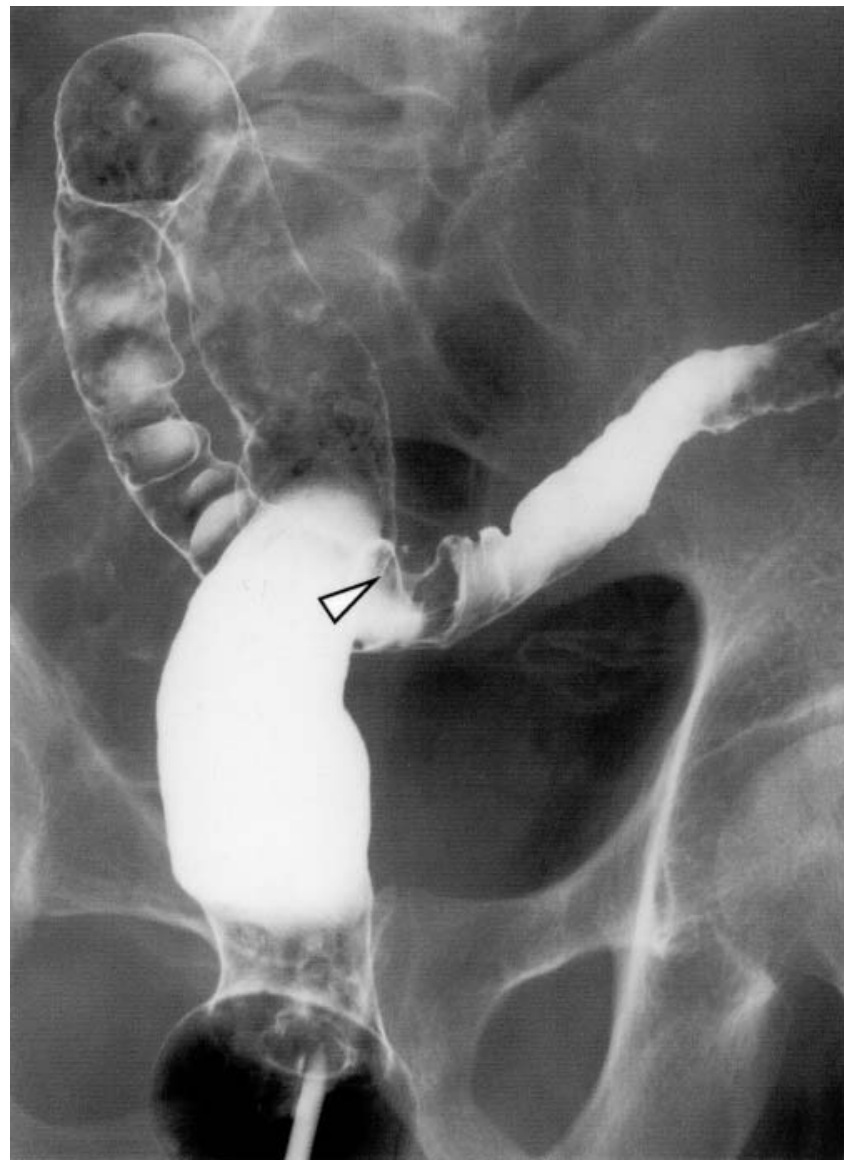

Figure 4. A $2.5-\mathrm{cm}$ mass lesion was recognized at the sigmoid colon (arrowhead).

case (Table 1). The reported causes of venous barium intravasation are diverticulum ( 9 cases), inflammatory colitis (5 cases: 3 of ulcerative colitis and 2 of Crohn's disease), and intestinal obstruction (5 cases). Wheatley and Eckhauser (19) reported that in almost every case out of 12 cases they reviewed, barium intravasation occurred because of mucosal defect. In the present case, multiple sigmoid ulcers were formed and made a colovenous fistula. Therefore the colonic contents leaked into vessels causing sepsis at the first time admission, and venous barium intravasation occurred during barium enema.

Reported regions of barium intravasation are the ileum (1 case), transverse colon ( 2 cases), sigmoid colon (11 cases including ours), rectosigmoid colon (2 cases), and rectum (7 cases). Barium almost always leaked into the portal circulation in patients with a mucosal defect of the ileum, transverse colon or sigmoid colon because colonic veins flow into the portal vein (Fig. 10). Barium almost always leaked into the systemic circulation in patients with a mucosal defect of the rectum because rectal veins flow mainly into the systemic circulation via the inferior and middle hemorrhoidal veins. Of the 9 patients with systemic circulation embolus, 7 died

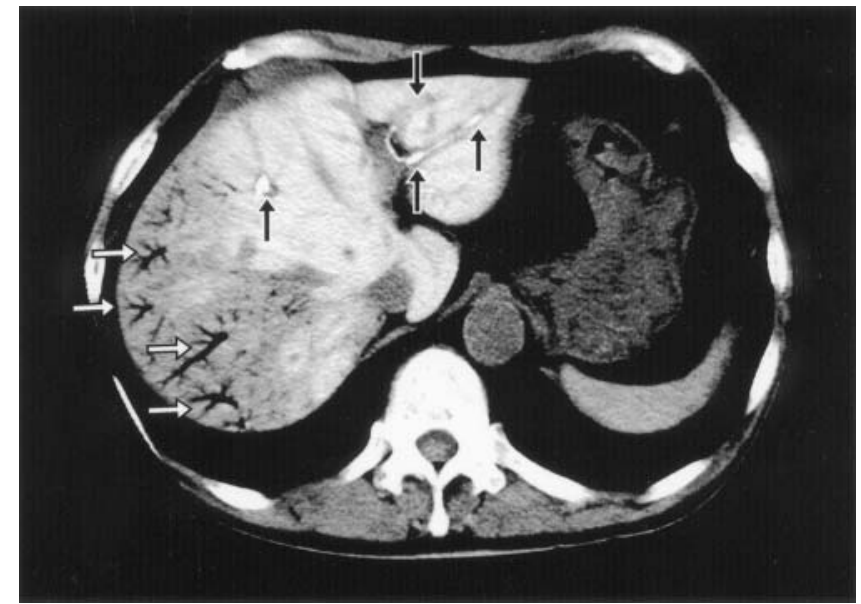

Figure 5. Unenhanced abdominal CT scan shows diffuse hyper density area, a few discrete barium emboli in the left lobe and anterior segment of the right lobe of the liver (black arrows) and air emboli in portal veins (white arrows).

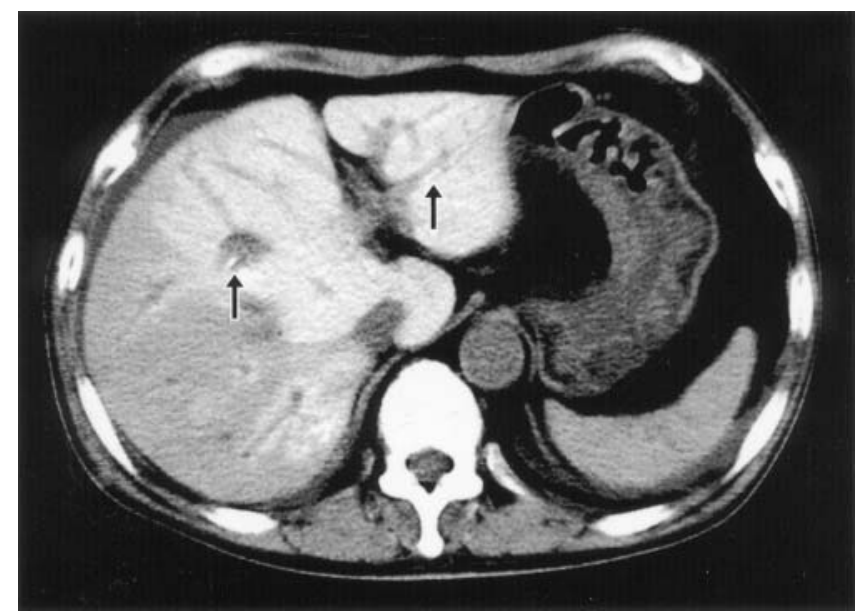

Figure 6. Unenhanced abdominal CT scan 24 hours after the enema; the air emboli in portal veins disappeared, but the diffuse hyper density area and barium emboli (arrows) did not change.

immediately with a massive embolus in the right side of the heart and/or pulmonary circulation (mortality $77.8 \%$ ), The other 2 patients survived because only a small amount of barium had become intravasated (18). Of the 14 patients with portal circulation embolus, 12 survived (mortality 14.3\%). One died from sepsis, and the other died from cancer (10, 22). When barium drains into the portal system, the liver seems to act as a filter, protecting against pulmonary embolism which may explain the increased survival of patients with portal circulation embolus.

We conclude that death in barium intravasation can result from massive systemic embolism and/or sepsis. If venous 


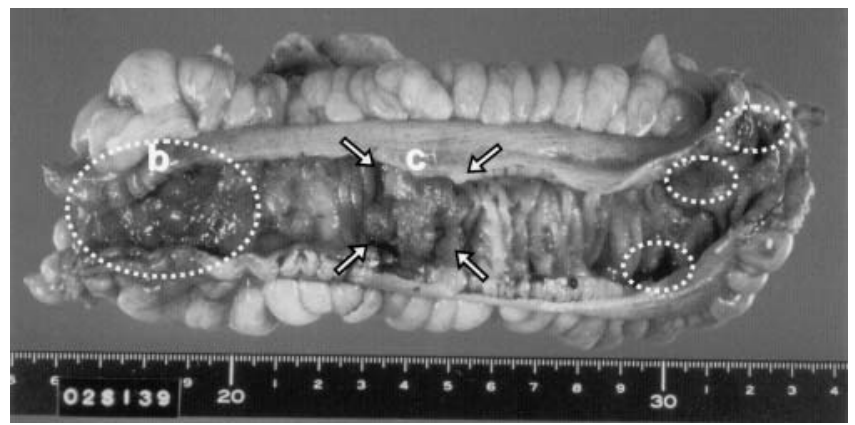

a

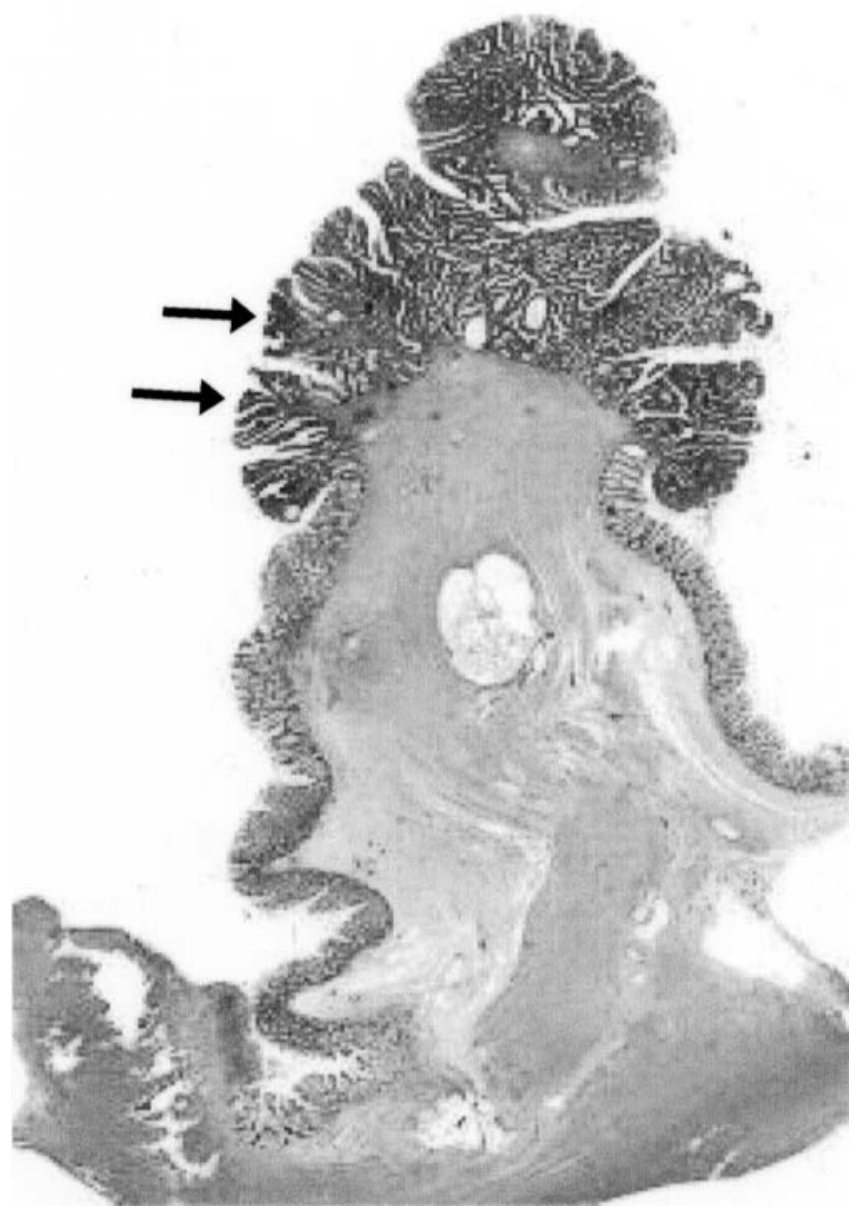

C

intravasation is observed, the flow of barium should be stopped and the barium should be drained from the rectum by gravity (18). Intravenous antibiotics should be given early to combat endotoxic shock (15). Surgery should then be undertaken to resect the site of intravasation. More importantly, barium enema examination should be used cautiously in patients with inflammatory bowel disease or diverticulitis. When a rectal mucosal defect is suspected, we suggest that water-soluble contrast medium be used to avoid emboliza-

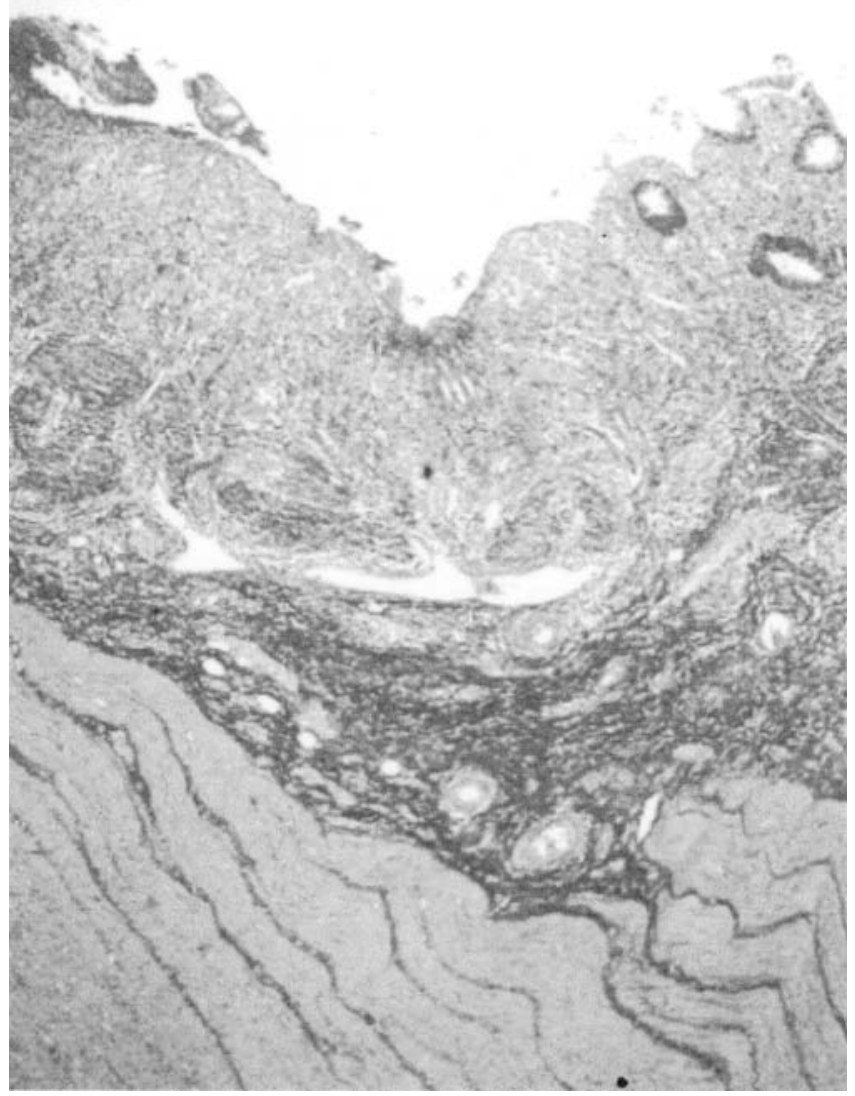

b

Figure 7. a) Resected sigmoid colon. Multiple ulcers (circles) and a polyp (arrows) are recognized. b) Microscopic section of the sigmoid colon ulcer (HE stain, $\times 10$ ). c) Microscope section of the sigmoid colon polyp. The polyp has carcinoma in situ (arrows) (Masson trichrome stain, $\times \mathbf{4 0}$ ). 

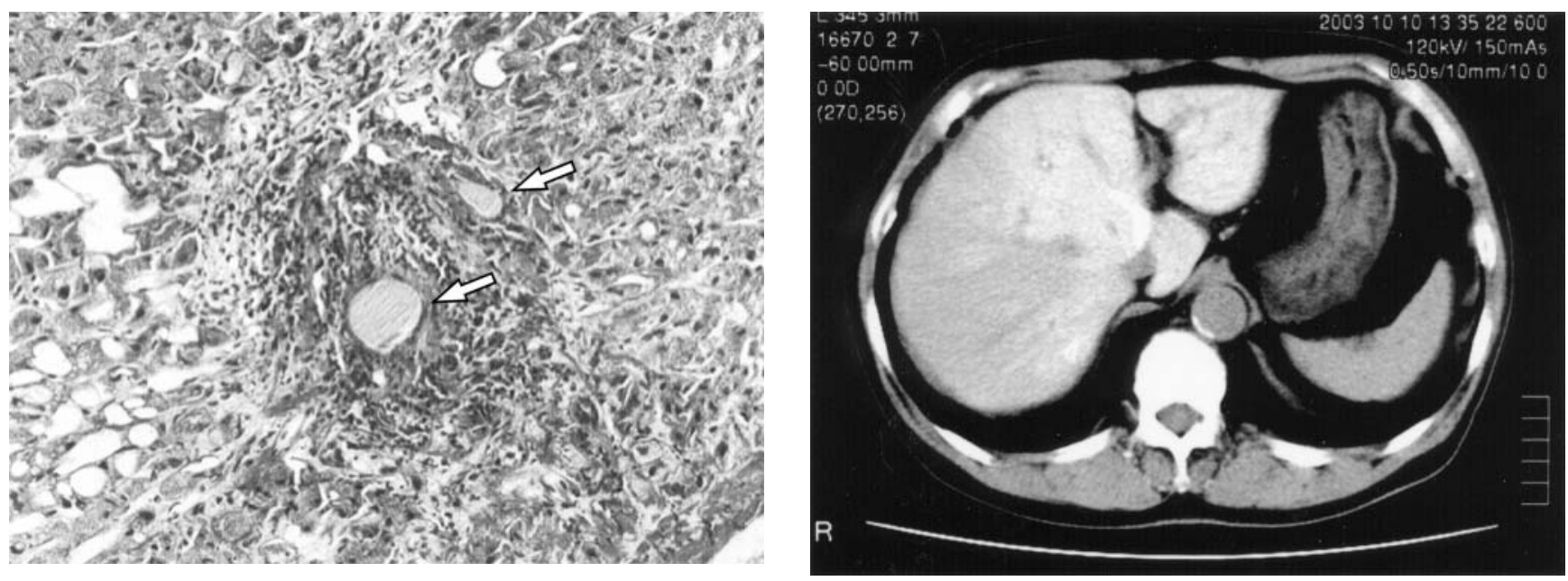

Figure 8. Intravascular barium (arrows) in lateral segment of the liver (Masson trichrome stain, $\times 120$ ).

Figure 9. 18 months later, follow-up CT scan reveals parenchymal infiltration of barium remaining in both the right and left hepatic lobes.

Table 1. Reported Cases of Barium Intravasation during Barium Enema

\begin{tabular}{|c|c|c|c|c|c|c|}
\hline \multirow[b]{2}{*}{ Authors } & \multicolumn{2}{|c|}{ Patient } & \multicolumn{2}{|c|}{ Embolus } & \multirow[b]{2}{*}{ Colonic disease } & \multirow[b]{2}{*}{ Outcome } \\
\hline & Age (y) & Sex & Origin & Site & & \\
\hline Issacs (1) & 25 & $\mathrm{~F}$ & Transverse & Portal & Ulcerative Colitis & Survived \\
\hline Roman (2) & 78 & $\mathrm{~F}$ & Rectum & Systemic & Obstruction & Died \\
\hline Rosenberg (3) & 73 & $\mathrm{~F}$ & Rectum & Systemic & (Evaluation of mass) & Died \\
\hline Truemner (4) & 76 & $\mathrm{~F}$ & Sigmoid & Systemic & Diverticulitis & Died \\
\hline Frecker (5) & 81 & $\mathrm{~F}$ & Rectum & Systemic & Constipation & Died \\
\hline Noveroske (6) & 72 & $\mathrm{~F}$ & Rectum & Systemic & Rectal bleeding & Died \\
\hline Nordahl (7) & 39 & M & Sigmoid & Portal & Diverticulitis & Survived \\
\hline Cove (8) & 64 & $\mathrm{~F}$ & Rectosigmoid & Systemic & Obstruction & Died \\
\hline Juler (9) & 35 & M & Sigmoid & Portal & Diverticulitis & Survived \\
\hline Salvo (10) & 36 & $\mathrm{~F}$ & Sigmoid & Portal & Diverticulitis & Died \\
\hline Schumacher (11) & 50 & M & Rectum & Portal & Obstruction & Survived \\
\hline Archer (12) & 86 & M & Stoma (sigmoid) & Portal & Obstruction & Survived \\
\hline Rothman (13) & 37 & M & Sigmoid & Portal & Diverticulitis & Survived \\
\hline Tsoutsanis (14) & 67 & M & Rectum & Systemic & Ulcerative Colitis & Died \\
\hline Blom (15) & 73 & $\mathrm{~F}$ & Rectum & Systemic & Diverticulitis & Survived \\
\hline Fowlie (16) & 38 & $\mathrm{~F}$ & Transverse & Portal & Crohn's Disease & Survived \\
\hline Kanehann (17) & 58 & M & Sigmoid & Portal & Diverticulitis & Survived \\
\hline Taylor (18) & 79 & $\mathrm{~F}$ & Sigmoid & Systemic & Obstruction & Survived \\
\hline Wheatley (19) & 27 & M & Rectosigmoid & Portal & Diverticulitis & Survived \\
\hline Payen (20) & 22 & M & Ileum & Portal & Crohn's Disease & Survived \\
\hline Zalev (21) & 29 & M & Sigmoid & Portal & Ulcerative Colitis & Survived \\
\hline Rossmann (22) & 32 & M & Sigmoid & Portal & Diverticulitis & Died \\
\hline Present case & 66 & M & Sigmoid & Portal & Colitis & Survived \\
\hline
\end{tabular}

F: Female, M: Male. 


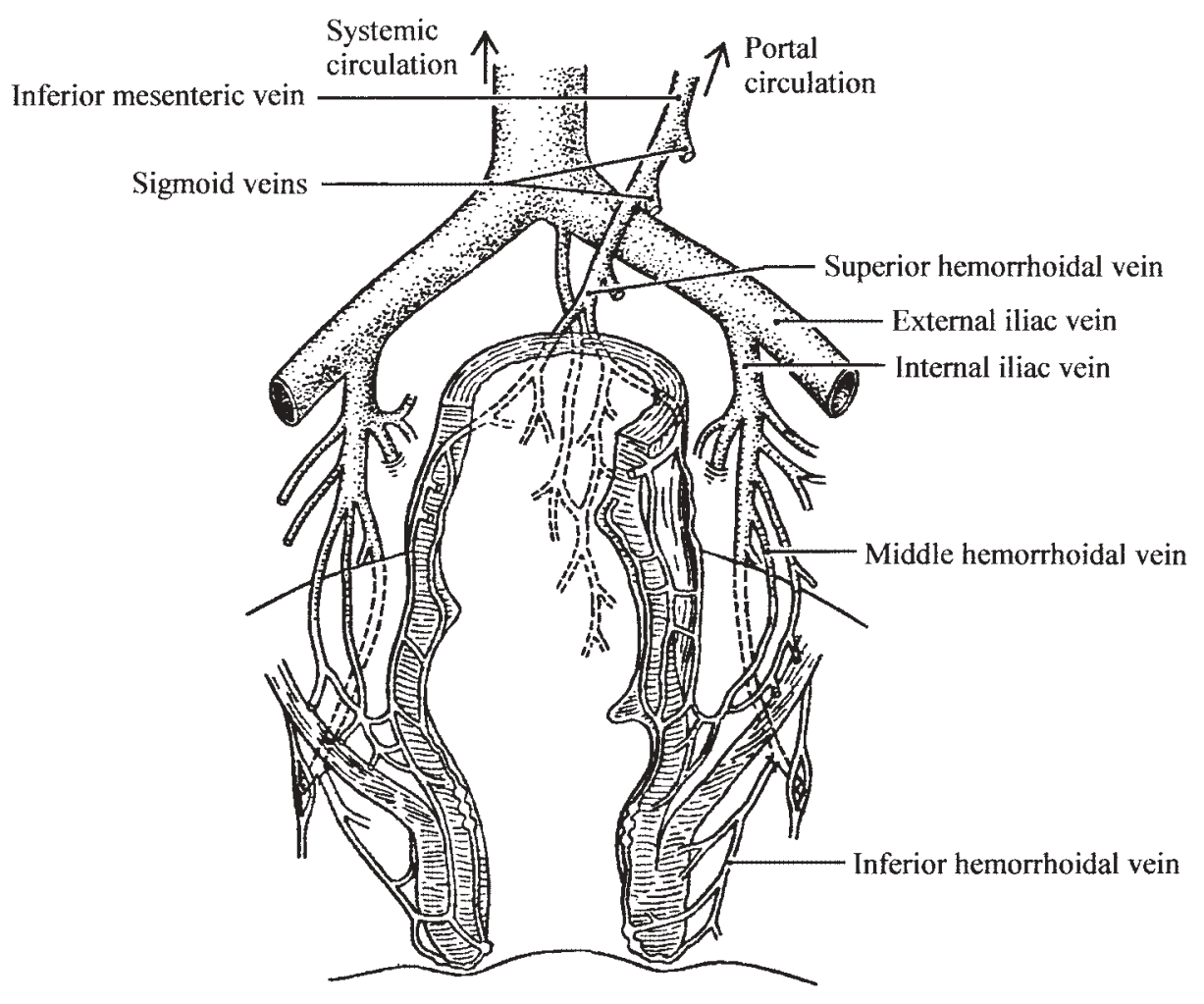

Figure 10. Anatomy of colonal and hemorrhoidal veins.

\section{References}

1) Issacs I, Nissen R, Epstein B.S. Liver abscess resulting from barium enema in a case of chronic ulcerative colitis. NY State J Med 50: 332334, 1950.

2) Roman PW, Wagner JH, Steinbach SH. Massive fatal embolism during barium enema study. Radiology 59: 190-192, 1952.

3) Rosenberg LS, Fine A. Fatal venous intravasation of barium during a barium enema. Radiology 73: 771-773, 1959.

4) Truemner KM, White $S$, Vanlandingham $H$. Fatal embolization of pulmonary capillaries. Report of a case associated with routine barium enema. JAMA 173: 1089-1092, 1960.

5) Frecker BE. Venous intravasation of the barium enema: report of a case. Australas Radiol 12: 129-132, 1968.

6) Noveroske RJ. Barium sulfate into the heart from extraperitoneal rupture of the rectosigmoid. J Indiana State Med Assoc 63: 32-33, 1970.

7) Nordahl DL, Siber FJ, Robbins AH, O'Hara ET. Non-fatal venous intravasation from the site of diverticulitis during barium enema examination. Am J Dig Dis 18: 253-256, 1973.

8) Cove JK, Snyder RN. Fatal Barium Intravasation during barium enema Radiology 112: 9-10, 1974.

9) Juler GL, Dietrick WR, Eisenman JI. Intramesenteric perforation of sigmoid diverticulitis with non-fatal venous intravasation. Am J Surg 132: 653-656, 1976

10) Salvo AF, Capron CW, Leigh KE, Dillihunt RC. Barium intravasation into portal venous system during barium enema examination. JAMA 235: 749-751, 1976.

11) Schumacher F. BaSO4 entrance into the inferior mesenteric veins during colonic contrast examination-a rare complication. ROFO Fortschr
Geb Rontgenstr Nuklearmed 133: 99-100, 1980 (Article in German).

12) Archer FH, Freeman AH. A case of non-fatal intravasation of barium during barium enema. Br J Radiol 54: 69-72, 1981.

13) Rothman BJ, Cloogman H, Wong D. Colovenous fistula complicating diverticulitis. Demonstration by contrast enema. Am J Gastroenterol 75: 464-468, 1981.

14) Tsoutsanis J. Intravasation of barium sulphate during roentgenography of the colon. Diagn Imaging 50: 1-3, 1981.

15) Blom H, Nauta EH, van Rosevelt RF, ten Cate JW. Disseminated intravascular coagulation and hypotension after intravasation of barium. Arch Intern Med 143: 1253-1255, 1983.

16) Fowlie S, Barton JR, Fraser GM. Barium embolization during barium enema examination: a report of a case and a review of the literature. $\mathrm{Br}$ J Radiol 60: 404-406, 1987.

17) Kanehann LB, Caroline DF, Friedman AC, Lev-Toaff AS, Radecki PD. CT findings in venous intravasation complicating diverticulitis. J Comput Assist Tomogr 12: 1047-1049, 1998.

18) Taylor DB, Yoong P. Non fatal barium intravasation during barium enema. Australas Radiol 34: 165-167, 1990.

19) Wheatley MJ, Eckhauser FE. Portal venous barium intravasation complicating barium enema examination. Surgery 109: 788-791, 1991.

20) Payen JL, Alric L, De Haldat F, et al. Enterovenous fistula. Gastroenterol Clin Biol 18: 78-80, 1994.

21) Zalev AH, Warren RE, Burnstein MJ. Venous intravasation of barium: CT findings. J Comput Assist Tomogr 17: 813-815, 1993.

22) Rossmann MD, Burr LJ, Thorpe PE. Colovenous fistula complicating diverticulitis: CT and radiographic findings. Abdom Imaging 22: 513$515,1997$. 